\title{
Parenteral amino acids $v$. dextrose infusion: an anabolic strategy to minimise the catabolic response to surgery while maintaining normoglycaemia in diabetes mellitus type 2 patients
}

\author{
Andrea Kopp Lugli ${ }^{1,2,3 *}$, Francesco Donatelli ${ }^{1,2}$, Thomas Schricker ${ }^{1}$, Christoph H. Kindler ${ }^{4}$, \\ Linda Wykes ${ }^{2}$ and Franco Carli ${ }^{1}$ \\ ${ }^{1}$ Department of Anaesthesia, McGill University, Montreal, Canada \\ ${ }^{2}$ School of Dietetics and Human Nutrition, McGill University, Montreal, Canada \\ ${ }^{3}$ Department of Anaesthesia and Intensive Care Medicine, University Hospital, Spitalstrasse 21, CH-4031 Basel, Switzerland \\ ${ }^{4}$ Department of Anaesthesia and Perioperative Medicine, Kantonsspital, Aarau, Switzerland
}

(Received 11 February 2011 - Revised 6 May 2011 - Accepted 6 May 2011 - First published online 17 August 2011)

\section{Abstract}

Loss of body protein and hyperglycaemia represent typical features of the stress response to surgery and anaesthesia. This appears to be particularly pronounced in patients with diabetes mellitus type 2 . The aim of the present study was to highlight the greater benefit of amino acids (AA) as represented by positive protein balance and maintenance of blood glucose homoeostasis compared with dextrose (DEX) in diabetic patients after colorectal surgery. A total of thirteen patients underwent a $5 \mathrm{~h}$ stable isotope infusion study $(2 \mathrm{~h}$ fasted, $3 \mathrm{~h}$ fed with an infusion of AA $(n 6)$ or DEX $(n 7)$ ) on the second post-operative day. Glucose and protein kinetics were assessed by using the stable isotopes $\mathrm{L}-\left[1-{ }^{13} \mathrm{C}\right]$ leucine and $\left[6,6-{ }^{2} \mathrm{H}_{2}\right]$ glucose. The transition from fasted to fed state decreased endogenous glucose production $(P<0 \cdot 001)$ in both groups, with a more profound effect in the DEX group $(P=0.031)$. In contrast, total glucose production was increased by the provision of DEX while being lowered by AA $(P=0 \cdot 021)$. Feeding decreased protein oxidation $(P=0 \cdot 009)$ and protein synthesis in the AA group, whereas DEX infusion did not affect oxidation and even decreased protein synthesis. Therefore, only AA shifted protein balance to a positive value, while patients in the DEX group remained in a catabolic state $(P<0 \cdot 001)$. Parenteral nutritional support with AA rather than with DEX is an effective strategy to achieve a positive protein balance while maintaining normoglycaemia in diabetic patients after colorectal surgery.

Key words: Diabetes mellitus type 2: Protein metabolism: Glucose metabolism: Nutritional support

Surgical injury provokes an endocrine metabolic stress response $^{(1)}$ inducing increased levels of stress hormones (cortisol, adrenaline, noradrenalin and glucagon) and decreased secretion and peripheral action of insulin ${ }^{(2)}$. This pathway causes a catabolic state including stereotypical metabolic alterations such as hyperglycaemia, enhanced lipolysis, increased muscle protein breakdown and amino acid (AA) oxidation $^{(3)}$. Since insulin resistance appears to play a role in these metabolic changes as well as in diabetes mellitus type 2 (DM2), it has been suggested that the catabolic stress responses to surgery may be exaggerated in DM2 patients ${ }^{(4,5)}$

Malnutrition in surgical patients is associated with higher rates of morbidity and mortality ${ }^{(6)}$. These concerns are emphasised in the population of diabetic patients undergoing gastrointestinal surgery, as they suffer from higher risk per se due to their metabolic disorder and the type of surgery.
Protein losses induced by the stress response to surgery can be attenuated by total parenteral nutrition, but only starving or malnourished patients with cancer benefit in the sense of a shift to anabolism ${ }^{(7)}$. Unselected iso- or hyperenergetic nutritional support in well-nourished surgical patients has no evidence-based indication and may even cause harm, as it is associated with increased morbidity ${ }^{(8)}$. Traditional strategies for patients after gastrointestinal surgery include fasting and intravenous fluids with hypoenergetic dextrose (DEX) until bowel motility is secured. However, hyperglycaemic levels, as possibly induced by DEX infusion, affect the immune system leading to an increased risk of infection and are related to an increased risk of post-operative complications in cardiac surgery ${ }^{(9)}$.

A previous study focusing on the metabolic response of patients with DM2 to major abdominal surgery reported

Abbreviations: AA, amino acids; DEX, dextrose; DM2, diabetes mellitus type 2; Ra, rate of appearance.

*Corresponding author: Dr A. Kopp Lugli, fax +4161265 73 20, email akopp@uhbs.ch 
marked protein catabolism as reflected by an increased oxidative protein loss in patients with DM2 compared with non-diabetics ${ }^{(4)}$. Although infusing DEX ( $4 \mathrm{mg} / \mathrm{kg}$ per min) did not affect protein metabolism in either group, plasma glucose levels were higher and endogenous glucose production was suppressed to a lesser extent in diabetic patients ${ }^{(4)}$. The provision of even low-dose DEX was accompanied by hyperglycaemia ${ }^{(10,11)}$, which has been associated with higher perioperative complication rates ${ }^{(9)}$. Therefore, subsequent trials provided nutritional support including AA with the goal of achieving a protein-sparing effect while maintaining normoglycaemia ${ }^{(12,13)}$. This anabolic effect of AA has been shown to be pronounced in diabetic patients receiving perioperative epidural analgesia compared with patient-controlled analgesia with morphine ${ }^{(12)}$, reinforcing the concept that the type of analgesia could be of importance in modulating the catabolic response to surgery ${ }^{(14)}$.

Based on these separately reported findings in diabetic patients $^{(4,12)}$, it was decided to analyse the data sub-sets of the diabetic groups having epidural analgesia from two previous investigations in order to directly compare the two nutritional support regimens based on the administration of AA $v$. DEX. The aim of the present study was to highlight the greater benefit of AA as represented by positive protein balance and maintenance of blood glucose homoeostasis compared with DEX alone in the vulnerable population of DM2 patients.

\section{Methods}

\section{Patients}

A total of thirteen patients with DM2 undergoing elective colorectal surgery, recruited in two previous studies conducted at the McGill University Health Centre, Montreal, Canada, were analysed. With the approval of the Ethics Committee of the Montreal General Hospital, written informed consent was obtained from six patients in the AA group ${ }^{(12)}$, and with the approval of the Ethics Committee of the Royal Victoria Hospital, Montreal, Canada written informed consent was obtained from seven patients in the DEX group ${ }^{(4)}$.

Inclusion criteria for both groups were age $>18$ years, DM2 (controlled by diet, oral hypoglycaemic medication or insulin) and colorectal surgery for non-metastatic disease (including right, transverse, left, sigmoid, subtotal, total and hemicolectomy and low anterior resection). Exclusion criteria were severe cardiac, hepatic, renal or metabolic disorders, diabetes mellitus type 1 , plasma albumin concentration $<35 \mathrm{~g} / 1$, more than $10 \%$ weight loss over the preceding 3 months, anaemia (haematocrit $<30 \%$ ), use of steroids, previous spinal surgery limiting the use of an epidural catheter and pregnancy. All patients received general anaesthesia combined with perioperative epidural analgesia.

\section{Anaesthesia and perioperative care}

The patients underwent bowel preparation on the day before surgery and were allowed to drink clear fluids until midnight.
The patients were operated during the morning hours by one of three surgeons who were informed of the study protocol. Oral hypoglycaemic medications were discontinued on the day of surgery. Perioperative glycaemic control was achieved by an insulin sliding scale aiming to maintain blood glucose levels between 5 and $10 \mathrm{mmol} / \mathrm{l}$. Blood glucose was measured every $6 \mathrm{~h}$. General anaesthesia was standardised: propofol/ thiopentone, fentanyl and rocuronium were used for induction and anaesthesia was maintained with nitrous oxide in oxygen and desflurane or isoflurane at end-tidal concentrations required to keep heart rate and blood pressure within $20 \%$ of pre-operative values.

An epidural catheter was inserted between thoracic vertebral levels T8-T11 before the induction of general anaesthesia. Neuraxial blockade was established with $0.5 \%$ bupivacaine to achieve a bilateral sensory block from thoracic dermatome level 4 to sacral dermatome level 1 . The blockade was maintained with an additional administration of $0.25 \%$ bupivacaine $(5-10 \mathrm{ml}$ boluses) during surgery. The sensory block from dermatomes T8 to L3 was post-operatively maintained for at least $48 \mathrm{~h}$ by continuous epidural infusion of $0 \cdot 1 \%$ bupivacaine supplemented with $2 \mu \mathrm{g} / \mathrm{ml}$ fentanyl. Pain levels at rest, during mobilisation and coughing were evaluated in all patients using an eleven-point visual analogue scale ( 0 , no pain; 10 , excruciating pain) every $4 \mathrm{~h}$ after surgery. Pain treatment was adjusted to achieve a visual analogue score level $<2$ at rest and $<5$ during mobilisation or coughing. All patients received hypoenergetic DEX (5\% in $1 / 4$ normal saline) on the first post-operative day until midnight when the infusion was changed to normal saline until the study period.

\section{Experimental protocol}

Beginning at 08.00 hours on the second day after surgery following overnight fasting and receiving only $0.9 \%$ normal saline from midnight on, the patients underwent a $5 \mathrm{~h}$ tracer kinetic study to characterise protein and glucose metabolism. The study consisted of a $2 \mathrm{~h}$ fasted state, which was followed by a $3 \mathrm{~h}$ fed state (Fig. 1). Plasma kinetics of leucine and glucose were determined using tracer quantities of L- $\left[1-{ }^{13} \mathrm{C}\right]$ leucine $\left(99 \%{ }^{13} \mathrm{C}\right)$ and $\left[6,6-{ }^{2} \mathrm{H}_{2}\right]$ glucose $\left(99 \%{ }^{2} \mathrm{H}\right)$ (Cambridge Isotope Laboratories, Cambridge, MA, USA). Sterile solutions of isotopes were prepared in the hospital pharmacy and kept at $4{ }^{\circ} \mathrm{C}$ until administration. Blood and expired breath samples were collected to determine baseline isotopic enrichments. Each blood sample was transferred immediately to a heparinised tube, centrifuged at $4^{\circ} \mathrm{C}$ $(2400 \boldsymbol{g} \times 10 \mathrm{~min})$ and stored at $-70^{\circ} \mathrm{C}$. Breath samples were collected in a 2 litre latex bag and transferred immediately to $10 \mathrm{ml}$ vacutainers (BD Vacutainer, Becton Dickinson, Franklin Lakes, NJ, USA). Sodium bicarbonate $\left(\mathrm{NaH}^{13} \mathrm{CO}_{3}\right.$; $0.08 \mathrm{mg} / \mathrm{kg}$ ) was administered orally. Priming doses of L- $\left[1-{ }^{13} \mathrm{C}\right]$ leucine $(4 \mu \mathrm{mol} / \mathrm{kg})$ and $\left[6,6-{ }^{2} \mathrm{H}_{2}\right]$ glucose $(22 \mu \mathrm{mol} / \mathrm{kg})$ were injected and followed immediately by continuous infusions of $\mathrm{L}-\left[1-{ }^{13} \mathrm{C}\right]$ leucine $0.06 \mu \mathrm{mol} / \mathrm{kg}$ per $\min$ and $\left[6,6-{ }^{2} \mathrm{H}_{2}\right]$ glucose $0 \cdot 22 \mu \mathrm{mol} / \mathrm{kg}$ per min lasting for $2 \mathrm{~h}$ (fasted state). For the subsequent $3 \mathrm{~h}$ period of the fed state, the 
Postoperative fast and feeding metabolism (08.00 hours $2 \mathrm{~d}$ after surgery)

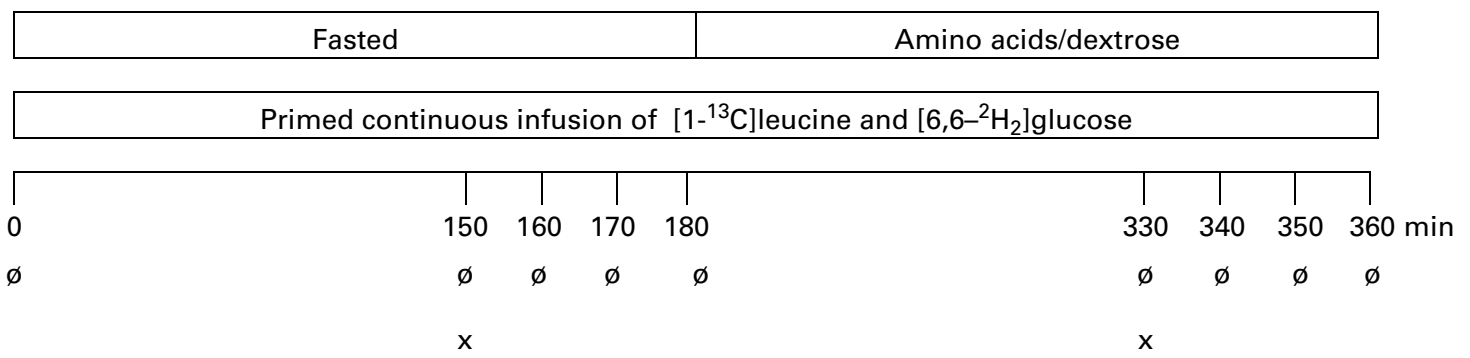

Fig. 1. Time course of the infusion of isotopes and collection of plasma and expired air samples (Ø) performed by indirect calorimetry ( $\square$ ), and collection of plasma for the determination of metabolic substrates and hormones $(x)$ in the fasted state and during the infusion of amino acids.

concentration of $\mathrm{L}-\left[1-{ }^{13} \mathrm{C}\right]$ leucine increased to $0 \cdot 12 \mu \mathrm{mol} / \mathrm{kg}$ per min and that of $\left[6,6-{ }^{2} \mathrm{H}_{2}\right]$ glucose was maintained at $0.22 \mu \mathrm{mol} / \mathrm{kg}$ per min in the AA group, whereas the concentration of $\left[6,6-{ }^{2} \mathrm{H}_{2}\right]$ glucose increased to $0.44 \mu \mathrm{mol} / \mathrm{kg}$ per min and that of $\mathrm{L}-\left[1-{ }^{13} \mathrm{C}\right]$ leucine was maintained at $0 \cdot 22 \mu \mathrm{mol} / \mathrm{kg}$ per min in the DEX group. During the fed state, a solution of crystallised beet sugar (10\% DEX anhydrous; Avebe, Foxhol, The Netherlands) was infused at $4 \mathrm{mg} / \mathrm{kg}$ per min in the DEX group. Patients in the AA group received a $10 \% \mathrm{AA}$ solution $^{(13)}$ without electrolytes (Travasol ${ }^{\mathrm{TM}}$, Baxter, Montreal, Canada) at a rate of $0.02 \mathrm{ml} / \mathrm{kg}$ per min (equivalent to $2.9 \mathrm{~g} / \mathrm{kg}$ per d) to achieve plasma AA concentrations at least two-fold above basal concentrations ${ }^{(15)}$. Both infusion rates are based on the European Society of Parenteral and Enteral Nutrition guidelines for protein and glucose intake ${ }^{(16)}$. Towards the end of each study period, four blood and breath samples were collected at $10 \mathrm{~min}$ intervals, when the tracers were assumed to have reached an isotopic steady state. Additional blood samples were drawn during the last $10 \mathrm{~min}$ of the fasted- and fed-state periods for the analysis of glucose, insulin, glucagon and cortisol. Indirect calorimetry (Vmax 29N; SensorMedics, Yorba Linda, CA, USA and Datex Deltatrac, Helsinki, Finland) was performed for $15 \mathrm{~min}$ in the last hour of the fasted and fed states of each tracer kinetic study period. The patients lay in a semi-recumbent position and breathed room air in a ventilated tent. Whole-body oxygen consumption $\left(\mathrm{VO}_{2}\right)$ and carbon dioxide production $\left(\mathrm{VCO}_{2}\right)$ were used to calculate respiratory quotient. Average values were used accepting a CV of less than $10 \%$ over $10 \min ^{(10)}$.

\section{Measurements}

Isotopic enrichments. Isotopic enrichment of plasma $\left[1-{ }^{13} \mathrm{C}\right] \alpha$-ketoisocaproate, representing the intracellular leucine pool, was used as the basis for calculating both leucine flux and the appearance from protein breakdown, as described previously $^{(17)}$. $\alpha$-Ketoisocaproate enrichment and plasma $\left[6,6-{ }^{2} \mathrm{H}_{2}\right]$ glucose enrichment were analysed by GC-MS ${ }^{(17,18)}$.

Plasma metabolites and hormones. Plasma glucose, serum insulin, glucagon and plasma cortisol were measured and analysed as described previously ${ }^{(4,12)}$.

Calculation of protein and glucose metabolism. Wholebody leucine and glucose kinetics were determined by conventional isotope dilution practice applying a two-pool stochastic model during steady-state conditions of the fasted and fed states after surgery ${ }^{(4)}$. The kinetics of the AA leucine, which makes up for $8 \%$ of whole-body protein, are representative of the dynamics of protein metabolism in the present study setting. Therefore, the terms 'protein synthesis' and 'protein balance' represent leucine kinetics and are used to present and discuss protein metabolism.

Under steady-state conditions, leucine flux $(Q)$ is defined by the formula: $Q=S+O=B+I$, where $S$ is the rate at which leucine is incorporated into the body protein, $O$ is the rate of leucine oxidation, $B$ is the rate at which unlabelled leucine enters the free AA pool from endogenous protein breakdown and $I$ is the rate of leucine intake including the tracer (rate of infusion of L- $\left[1-{ }^{13} \mathrm{C}\right]$ leucine; $\mu \mathrm{mol} / \mathrm{kg}$ per $\mathrm{h}$ ) and diet. The calculation of the values for glucose and protein metabolism was performed as described previously ${ }^{(13)}$.

\section{Statistical analysis}

The longitudinal data with one independent factor 'type of feeding' and two time points (fasted $v$. fed) were analysed with a Brunner-Langer model with an ANOVA-type statistic. Statistical analyses were conducted using the SAS System 9.1 (SAS Institute, Cary, NC, USA). A significance level of 0.05 was used for all tests.

\section{Results}

\section{Patients}

There were no significant differences regarding sex, age, height, weight, BMI and duration of surgery in both groups (Table 1). The pain scores measured by the visual analogue scale never exceeded the value of 4 , and no patient complained about severe pain.

\section{Glucose and protein kinetics}

Fasting glucose kinetics were comparable in both groups (Table 2). The main effect of feeding was to decrease endogenous glucose production (endogenous rate of appearance (Ra) of glucose; $P<0 \cdot 001)$. The transition from fasted to 
Table 1. Demographic data of patients

(Mean values and standard deviations)

\begin{tabular}{|c|c|c|c|c|}
\hline & \multicolumn{2}{|c|}{ Amino acids } & \multicolumn{2}{|c|}{ Dextrose } \\
\hline & Mean & $\overline{S D}$ & Mean & $\overline{S D}$ \\
\hline Number of patients & \multicolumn{2}{|c|}{6} & \multicolumn{2}{|c|}{7} \\
\hline Age (years) & 74 & 9 & 68 & 5 \\
\hline Height $(\mathrm{cm})$ & 173 & 11 & 167 & 7 \\
\hline Weight (kg) & $86 \cdot 5$ & $21 \cdot 8$ & $70 \cdot 9$ & 5.4 \\
\hline $\operatorname{BMI}\left(\mathrm{kg} / \mathrm{m}^{2}\right)$ & $28 \cdot 9$ & $5 \cdot 8$ & $25 \cdot 4$ & $1 \cdot 8$ \\
\hline \multicolumn{5}{|l|}{ Sex } \\
\hline Male & \multicolumn{2}{|c|}{5} & \multicolumn{2}{|c|}{4} \\
\hline Female & \multicolumn{2}{|c|}{1} & \multicolumn{2}{|c|}{3} \\
\hline \multicolumn{5}{|l|}{ ASA (I/II/III) } \\
\hline 1 & \multicolumn{2}{|c|}{0} & \multicolumn{2}{|c|}{0} \\
\hline II & \multicolumn{2}{|c|}{3} & \multicolumn{2}{|c|}{4} \\
\hline III & \multicolumn{2}{|c|}{3} & \multicolumn{2}{|c|}{3} \\
\hline \multicolumn{5}{|l|}{ Type of surgery } \\
\hline Hemicolectomy/colectomy & \multirow{2}{*}{\multicolumn{2}{|c|}{$\begin{array}{l}2 \\
4\end{array}$}} & \multirow{2}{*}{\multicolumn{2}{|c|}{3}} \\
\hline Anterior resection & & & 4 & \\
\hline Duration of surgery (min) & 167 & 93 & 214 & 57 \\
\hline \multicolumn{5}{|l|}{ Type of diabetes treatment } \\
\hline Diet & \multicolumn{2}{|c|}{1} & \multicolumn{2}{|c|}{2} \\
\hline OAD & \multirow{2}{*}{\multicolumn{2}{|c|}{$\begin{array}{l}4 \\
1\end{array}$}} & \multirow{2}{*}{\multicolumn{2}{|c|}{$\begin{array}{l}5 \\
0\end{array}$}} \\
\hline Insulin & & & & \\
\hline
\end{tabular}

ASA, American Society of Anesthesiologists classification; OAD, oral anti-diabetic drugs.

fed state lowered the endogenous $\mathrm{Ra}$ of glucose to a greater extent in the DEX group compared with that in the AA group $(P=0.031)$, whereas total glucose production (total Ra of glucose) was higher in the DEX group compared with the AA group $(P=0 \cdot 021)$. DEX infusion decreased the endogenous Ra of glucose dramatically while increasing the total $\mathrm{Ra}$ of glucose. In contrast, AA infusion decreased both endogenous $\mathrm{Ra}$ and total $\mathrm{Ra}$ of glucose $(P=0.034$ and $P<0.001$, respectively). The transition from fasted to fed state decreased glucose clearance $(P<0.001)$, with a more profound effect for the AA group $(P=0.003)$.

Fasting AA kinetics (Table 3) were similar in both groups except for leucine oxidation (DEX group: 29 (SD 9) $\mu \mathrm{mol} / \mathrm{kg}$ perh; AA group: 15 (SD 5) $\mu \mathrm{mol} / \mathrm{kg}$ per h; $P=0.005$ ), resulting in a less negative protein balance in the AA group compared with the DEX group (DEX group: -29 (SD 9) $\mu \mathrm{mol} / \mathrm{kg}$ per h; AA group: -15 (SD 5) $\mu \mathrm{mol} / \mathrm{kg}$ per $\mathrm{h}$ ). The main effect of feeding was a decrease in endogenous $\mathrm{Ra}$ of leucine
$(P=0 \cdot 016)$. The type of nutrition had a greater impact on leucine oxidation in the AA group, showing an increase when compared with the constant values in the DEX group $(P=0.009)$. The infusion of AA, therefore, shifted protein balance to a positive value, whereas patients in the DEX group remained in a net catabolic state $(P=0.025)$. This contrasting effect was mainly attributed to the type of feeding $(P<0 \cdot 001)$.

\section{Gaseous exchange}

Gaseous exchange values were comparable for the groups in the fasted state. No significant changes were observed by the effect of nutrition or type of nutrition (Table 4).

\section{Plasma hormones and metabolites}

Hormones and metabolites (Table 5) were also affected by feeding. Feeding increased plasma glucose $(P<0 \cdot 001)$ and insulin $(P=0.009)$, resulting in hyperglycaemia in the DEX group and normoglycaemia in the AA group $(P=0.063$ for the type of feeding and $P=0.001$ for the interaction). Feeding provoked an increase in glucagon in the AA group and a decrease in the DEX group $(P=0 \cdot 03)$. The insulin:glucagon ratio increased to a greater extent during DEX infusion compared with AA provision $(P=0.013)$. When using the homoeostasis model assessment (HOMA) to account for insulin sensitivity, feeding increased the HOMA values in both groups $(P<0 \cdot 001)$.

\section{Discussion}

The present results suggest that an intravenous infusion of AA prevents pronounced hyperglycaemia in diabetic patients after colorectal surgery. This is in accordance with the state of insulin resistance observed in patients with diabetes mellitus, resulting in limited suppressibility of endogenous glucose production and abnormal peripheral glucose utilisation ${ }^{(19)}$. Furthermore, a positive protein balance can be achieved, whereas DEX infusion alone does not affect protein metabolism and the patients remain in a net catabolic state.

Endogenous glucose supply is based on glycogenolysis and gluconeogenesis. Overnight fasting leads to post-absorptive

Table 2. Kinetics of glucose metabolism in the fasted and fed state for the dextrose (DEX) and amino acid (AA) groups

(Mean values and standard deviations, $n 7$ for the DEX group and $n 6$ for the AA group)

\begin{tabular}{|c|c|c|c|c|c|c|c|c|c|c|c|}
\hline \multirow[b]{3}{*}{ Variable } & \multicolumn{4}{|c|}{ DEX } & \multicolumn{4}{|c|}{ AA } & & & \\
\hline & \multicolumn{2}{|c|}{ Fasted } & \multicolumn{2}{|c|}{ Fed } & \multicolumn{2}{|c|}{ Fasted } & \multicolumn{2}{|c|}{ Fed } & \multicolumn{3}{|c|}{$P$} \\
\hline & Mean & SD & Mean & SD & Mean & SD & Mean & SD & $\begin{array}{l}\text { Feeding } \\
\text { state* }^{*}\end{array}$ & $\begin{array}{c}\text { Type of } \\
\text { nutrition }\end{array}$ & Interaction $\ddagger$ \\
\hline $\begin{array}{l}\text { Endogenous rate of appearance } \\
\text { of glucose ( } \mu \mathrm{mol} / \mathrm{kg} \text { per min) }\end{array}$ & $15 \cdot 3$ & $2 \cdot 1$ & $3 \cdot 9$ & $1 \cdot 2$ & $17 \cdot 3$ & 3.3 & $12 \cdot 2$ & 3.2 & $<0.001$ & 0.031 & 0.034 \\
\hline $\begin{array}{l}\text { Total rate of appearance of } \\
\text { glucose }(\mu \mathrm{mol} / \mathrm{kg} \text { per min })\end{array}$ & $15 \cdot 3$ & $2 \cdot 1$ & $24 \cdot 6$ & 1.8 & $17 \cdot 3$ & $3 \cdot 3$ & $12 \cdot 2$ & $3 \cdot 2$ & 0.069 & 0.021 & $<0.001$ \\
\hline Glucose clearance (ml/kg per $\mathrm{min}$ ) & $2 \cdot 1$ & 0.5 & $1 \cdot 8$ & 0.4 & $2 \cdot 4$ & 0.4 & $1 \cdot 6$ & 0.3 & $<0.001$ & 0.917 & 0.003 \\
\hline
\end{tabular}

* Probability that values are influenced by parenteral alimentation.

†Probability that values are influenced by the type of nutrition.

$\ddagger$ Probability that the effect of type of nutrition is greater in one group. 
Table 3. Kinetics of protein metabolism in the fasted and fed state for the dextrose (DEX) and amino acid (AA) groups

(Mean values and standard deviations, $n 7$ for the DEX group and $n 6$ for the AA group)

\begin{tabular}{|c|c|c|c|c|c|c|c|c|c|c|c|}
\hline \multirow[b]{3}{*}{ Variable $(\mu \mathrm{mol} / \mathrm{kg}$ per $\mathrm{h})$} & \multicolumn{4}{|c|}{ DEX } & \multicolumn{4}{|c|}{ AA } & & & \\
\hline & \multicolumn{2}{|c|}{ Fasted } & \multicolumn{2}{|c|}{ Fed } & \multicolumn{2}{|c|}{ Fasted } & \multicolumn{2}{|c|}{ Fed } & \multicolumn{3}{|c|}{$P$} \\
\hline & Mean & SD & Mean & $\mathrm{SD}$ & Mean & SD & Mean & SD & Feeding state ${ }^{*}$ & Type of nutritiont & Interaction $\ddagger$ \\
\hline Rate of appearance of Leu & 133 & 26 & 120 & 15 & 123 & 19 & 142 & 25 & 0.832 & 0.507 & 0.128 \\
\hline $\begin{array}{l}\text { Endogenous rate of appearance of } \\
\text { Leu (net protein breakdown) }\end{array}$ & 133 & 26 & 120 & 15 & 123 & 19 & 88 & 25 & 0.016 & $0 \cdot 126$ & $0 \cdot 118$ \\
\hline Leu oxidation & 29 & 9 & 29 & 5 & 15 & 5 & 24 & 8 & 0.041 & 0.009 & 0.16 \\
\hline Protein synthesis of Leu & 104 & 21 & 92 & 16 & 108 & 19 & 117 & 21 & 0.926 & 0.136 & 0.116 \\
\hline Protein balance of Leu & -29 & 9 & -29 & 5 & -15 & 5 & 30 & 8 & 0.12 & $<0.001$ & 0.025 \\
\hline
\end{tabular}

* Probability that values are influenced by parenteral alimentation.

†Probability that values are influenced by the type of nutrition.

$\ddagger$ Probability that the effect of type of nutrition is greater in one group.

conditions, where glycogenolysis and gluconeogenesis each provide about half of the whole-body glucose production ${ }^{(20)}$. With ongoing fasting, gluconeogenesis increases gradually and contributes up to $90 \%$ of glucose production after $42 \mathrm{~h}$ in non-diabetic patients ${ }^{(21)}$. In a more moderate manner, these adaptations are also observed in patients with $\mathrm{DM} 2^{(5,22)}$ and in well-nourished patients with malignant diseases ${ }^{(23)}$. The present findings are consistent with these reports, as the endogenous $\mathrm{Ra}$ of glucose is about $35 \%$ higher in diabetic patients compared with that in non-diabetic patients in post-absorptive conditions ${ }^{(10,11,13)}$. The inhibitory effect of exogenous glucose on endogenous glucose production depends on the amount of glucose infused and the patient's metabolic state. This is also reflected by a reduced suppression of endogenous glucose production in septic or traumatised patients ${ }^{(24,25)}$. Furthermore, altered glucose homoeostasis predisposes hyperglycaemic myocardial tissue to injury during ischaemia, and insulin resistance has been shown to be an independent risk factor of in-hospital mortality following acute myocardial infarction ${ }^{(26)}$. It must be noted that such a reduction in endogenous glucose production due to exogenous administration of glucose is most pronounced in post-operative diabetic patients ${ }^{(4)}$. In general, AA infusion during the post-operative period effectively reduces endogenous glucose production in non-diabetic patients ${ }^{(13,27)}$. In the present study, this reduction in endogenous glucose production in diabetic patients due to AA infusion was more pronounced than previously reported in non-diabetic patients ${ }^{(13)}$. Therefore, it may be hypothesised that AA infusion suppresses the endogenous rate of appearance of leucine, i.e. proteolysis, because less AA are required for gluconeogenesis independent of the effect of insulin.

The anti-catabolic effect of insulin depends on the state of peripheral resistance, mainly through the inhibition of muscle protein breakdown ${ }^{(28)}$. In patients with diabetes mellitus type 1 , protein breakdown and oxidation are increased, whereas in DM2 patients with good or moderate glucose control, the rate of appearance of leucine and protein breakdown is normal ${ }^{(29)}$. Furthermore, in poorly controlled and obese DM2 patients, protein breakdown was higher than in their non-diabetic counterparts ${ }^{(30)}$, and leucine oxidation has not been shown to be increased ${ }^{(5)}$. In the fasted state, discrepant results regarding leucine oxidation were detectable, as the DEX group clearly showed higher leucine oxidation compared with previously published results in non-diabetic patients, whereas this value was slightly lower in the AA group than in non-diabetic patients ${ }^{(10,11,13)}$. A possible explanation and limitation of the present study was not having determined HbA1c before surgery. However, the pre-operative plasma glucose concentrations indicated good or moderate control in both groups. A previous study reported that hyperglucagonaemia appears to be primarily responsible for increased leucine oxidation in diabetes type 1 patients ${ }^{(31)}$. However, glucagon levels during the fasted state were comparable in

Table 4. Gaseous exchange in the fasted and fed state for the dextrose (DEX) and amino acid (AA) groups

(Mean values and standard deviations, $n 7$ for the DEX group and $n 6$ for the AA group)

\begin{tabular}{|c|c|c|c|c|c|c|c|c|c|c|c|}
\hline \multirow[b]{3}{*}{ Variable } & \multicolumn{4}{|c|}{ DEX } & \multicolumn{4}{|c|}{ AA } & & & \\
\hline & \multicolumn{2}{|c|}{ Fasted } & \multicolumn{2}{|c|}{ Fed } & \multicolumn{2}{|c|}{ Fasted } & \multicolumn{2}{|c|}{ Fed } & \multicolumn{3}{|c|}{$P$} \\
\hline & Mean & SD & Mean & SD & Mean & SD & Mean & SD & Feeding state ${ }^{*}$ & Type of nutrition† & Interaction‡ \\
\hline $\mathrm{VO}_{2}(\mathrm{ml} / \mathrm{min})$ & 252 & 54 & 242 & 46 & 262 & 27 & 295 & 78 & 0.888 & 0.188 & 0.417 \\
\hline $\mathrm{VCO}_{2}(\mathrm{ml} / \mathrm{min})$ & 189 & 41 & 183 & 35 & 194 & 26 & 209 & 50 & 0.756 & 0.399 & 0.328 \\
\hline$R Q$ & 0.75 & 0.02 & 0.76 & 0.02 & 0.74 & 0.05 & 0.72 & 0.11 & 0.845 & 0.281 & 0.38 \\
\hline
\end{tabular}

$\mathrm{VO}_{2}$, oxygen consumption; $\mathrm{VCO}_{2}$, carbon dioxide production; $\mathrm{RQ}$, respiratory quotient.

* Probability that values are influenced by parenteral alimentation.

†Probability that values are influenced by the type of nutrition.

$\ddagger$ Probability that the effect of type of nutrition is greater in one group. 
both groups. Additionally, it could be argued that the DEX group included patients with a wider range of insulin sensitivity as represented by homoeostasis model assessment (HOMA) in the fasted state.

The relative concentrations of insulin and glucagon control the hepatic glucose balance ${ }^{(32)}$. The insulin:glucagon ratio is inversely correlated with increased glucose production in the liver. A high ratio indicates glucose storage and increased protein synthesis, whereas a low ratio is a sign of increased gluconeogenesis from AA. In a previous study, comparing diabetic patients with non-diabetic patients after colorectal surgery, lower insulin concentrations were found to be accompanied by higher glucagon levels in the diabetic group. Furthermore, negative correlations between the insulin:glucagon ratio and glucose production as well as AA oxidation led to the conclusion that these changes might be attributed to alterations in the insulin:glucagon system ${ }^{(4)}$. The present study revealed higher levels of insulin in the fasted as well as in the fed state for the DEX group, whereas glucagon decreased in the DEX group and increased in the AA group during feeding, resulting in a higher insulin:glucagon ratio in patients of the DEX group.

Infusion of AA increased the Ra of leucine, leucine oxidation, as well as protein synthesis accompanied by a reduced net protein breakdown, resulting in a positive protein balance. In contrast, the administration of DEX did not affect protein kinetics, and the protein balance remained negative in the fed state. The patients receiving AA showed a net leucine balance in the fed state that was $59 \mu \mathrm{mol} / \mathrm{kg}$ per h higher than in the patients receiving glucose. Assuming body protein contains $8 \%$ leucine, this translates to savings of $140 \mathrm{~g}$ protein in a $70 \mathrm{~kg}$ person in $1 \mathrm{~d}$. The potential impact on lean body mass and functional outcomes in post-operative patients was not assessed in the present study. However, the present findings are consistent with the observations in non-diabetic patients, although the protein balance even appears to be improved to a greater extent in diabetic patients ${ }^{(13)}$. With regard to post-operative morbidity and mortality, a previous large clinical trial indicated no justification of routine proteinsparing therapy for normonourished or mildly malnourished patients undergoing major abdominal surgery ${ }^{(33)}$. However, the present study included an oral starvation period of $5 \mathrm{~d}$ in a heterogeneous cohort and lacks both a metabolic analysis and the inclusion of diabetic patients. Taking into account the evolution of today's clinical practice promoting a fast track approach with early oral feeding, future studies focusing on lipid metabolism, early post-operative feeding and provision of micronutrients and immunonutrition might offer additional insight into the optimal perioperative nutritional support.

In summary, the present study of two types of feeding in diabetic patients after colorectal surgery underscores the anabolic benefits of AA while possibly preventing hyperglycaemia-induced comorbidities associated with DEX infusion. Therefore, a peripheral intravenous provision of AA in a perioperative setting of major abdominal surgery in diabetic or malnourished patients with only short oral fasting periods might be considered to improve nutritional support of these 
patients. However, the perioperative provision of AA with respect to improved outcomes in clearly defined patient groups requires further investigation.

\section{Acknowledgements}

We gratefully acknowledge Mrs Louise Mazza, B.Sc. (Technician, Department of Anaesthesia, McGill University, Royal Victoria Hospital, Montreal, Canada) for excellent technical assistance and Professor Hüsler and Dr Zumbrunnen (Institute of Mathematical Statistics and Actuarial Science, University of Berne, Switzerland) for statistical support. The authors also thank Patrick Charlebois, MD, Sarkis Meterissian, MD and Barry Stein, MD (Assistant Professors, Department of Surgery, McGill University Health Centre, Montreal, Canada) for allowing their patients to be studied. The present study was supported by the Swiss National Science Foundation, Zurich, Switzerland; the Kantonsspital Aarau, Switzerland; Fresenius Switzerland; the European Society of Anaesthesiology; the McGill University Health Centre Foundation Fellowship, Montreal, Canada; the Canadian Institutes of Health Research, Ottawa, Canada; and the Fonds de la Recherché en Santé Quebec (FRSQ), Canada. A. K. L. is the recipient of a study grant (PBZHB-110303) of the Swiss National Science Foundation, Zurich, Switzerland, the Kantonsspital Aarau, Switzerland (no specific grant number) and Fresenius Switzerland (no specific grant number). F. D. was the recipient of a study grant of the European Society of Anaesthesia (ESA Research Grant 2005, no. 2) and of the McGill University Health Centre Foundation Fellowship (no specific grant number), Montreal, Canada. T. S. is supported by grants from the Canadian Institutes of Health Research (MOP 64456), Ottawa, Canada and the Fonds de la recherche en santé Quebec (FRSQ) (no specific grant number), Canada. None of the authors has any conflict of interest. A. K. L. designed and conducted the study, and supervised data collection and analysis, data interpretation and manuscript writing. F. D. and F. C. designed and conducted the study, and were involved in the data collection and analysis, data interpretation and editing the manuscript. C. H. K. participated in data interpretation and editing the manuscript. L. W. designed the study, conducted the data analysis and data interpretation, and edited the manuscript. T. S. designed the study, and was involved in data interpretation and editing the manuscript. None of the authors has any conflict of interest.

\section{References}

1. Holte K \& Kehlet H (2002) Epidural anaesthesia and analgesia - effects on surgical stress responses and implications for postoperative nutrition. Clin Nutr 21, 199-206.

2. Deibert DC \& DeFronzo RA (1980) Epinephrine-induced insulin resistance in man. J Clin Invest 65, 717-721.

3. Kinney J (1983) Metabolic response to injuries. In Nutritional Support of the Seriously Ill Patient [R Winters and H Green, editors]. New York: Academic Press.

4. Schricker T, Gougeon R, Eberhart L, et al. (2005) Type 2 diabetes mellitus and the catabolic response to surgery. Anesthesiology 102, 320-326.
5. Richardson AP \& Tayek JA (2002) Type 2 diabetic patients may have a mild form of an injury response: a clinical research center study. Am J Physiol Endocrinol Metab 282, E1286-E1290.

6. Detsky AS, Baker JP, O'Rourke K, et al. (1987) Predicting nutrition-associated complications for patients undergoing gastrointestinal surgery. JPEN J Parenter Enteral Nutr 11, 440-446.

7. Wilmore DW (1991) Catabolic illness. Strategies for enhancing recovery. $N$ Engl J Med 325, 695-702.

8. Anonymous (1988) Veterans Administration cooperative trial of perioperative total parenteral nutrition in malnourished surgical patients. Background, rationale, and study protocol. Am J Clin Nutr 47, Suppl. 2, 351-391.

9. Krinsley J (2006) Perioperative glucose control. Curr Opin Anaesthesiol 19, 111-116.

10. Schricker T, Wykes L \& Carli F (2000) Epidural blockade improves substrate utilization after surgery. Am J Physiol Endocrinol Metab 279, E646-E653.

11. Schricker T, Wykes L, Eberhart L, et al. (2002) The anabolic effect of epidural blockade requires energy and substrate supply. Anesthesiology 97, 943-951.

12. Kopp Lugli A, Donatelli F, Schricker T, et al. (2008) Epidural analgesia enhances the postoperative anabolic effect of amino acids in diabetes mellitus type 2 patients undergoing colon surgery. Anesthesiology 108, 1093-1099.

13. Donatelli F, Schricker T, Mistraletti G, et al. (2006) Postoperative infusion of amino acids induces a positive protein balance independently of the type of analgesia used. Anesthesiology 105, 253-259.

14. Anderson RE, Ehrenberg J, Barr G, et al. (2005) Effects of thoracic epidural analgesia on glucose homeostasis after cardiac surgery in patients with and without diabetes mellitus. Eur J Anaesthesiol 22, 524-529.

15. Castellino P, Luzi L, Simonson DC, et al. (1987) Effect of insulin and plasma amino acid concentrations on leucine metabolism in man. Role of substrate availability on estimates of whole body protein synthesis. J Clin Invest 80, 1784-1793.

16. Braga M, Ljungqvist $O$, Soeters $P$, et al. (2009) ESPEN guidelines on parenteral nutrition: surgery. Clin Nutr 28, 378-386.

17. Schricker T, Klubien K, Wykes L, et al. (2000) Effect of epidural blockade on protein, glucose, and lipid metabolism in the fasted state and during dextrose infusion in volunteers. Anesthesiology 92, 62-69.

18. Mackenzie ML, Warren MR \& Wykes LJ (2003) Colitis increases albumin synthesis at the expense of muscle protein synthesis in macronutrient-restricted piglets. J Nutr $\mathbf{1 3 3}$ 1875-1881.

19. Mevorach M, Giacca A, Aharon Y, et al. (1998) Regulation of endogenous glucose production by glucose per se is impaired in type 2 diabetes mellitus. J Clin Invest 102, $744-753$.

20. Landau BR, Wahren J, Chandramouli V, et al. (1996) Contributions of gluconeogenesis to glucose production in the fasted state. J Clin Invest 98, 378-385.

21. Chandramouli V, Ekberg K, Schumann WC, et al. (1997) Quantifying gluconeogenesis during fasting. Am J Physiol 273, 6 Pt 1, E1209-E1215.

22. Basu R, Schwenk WF \& Rizza RA (2004) Both fasting glucose production and disappearance are abnormal in people with "mild" and "severe" type 2 diabetes. Am J Physiol Endocrinol Metab 287, E55-E62.

23. Humberstone DA \& Shaw JH (1998) Metabolism in hematologic malignancy. Cancer 62, 1619-1624.

24. Shaw JH, Klein S \& Wolfe RR (1985) Assessment of alanine, urea, and glucose interrelationships in normal subjects and 
in patients with sepsis with stable isotopic tracers. Surgery 97, 557-568.

25. Shaw JH \& Wolfe RR (1989) An integrated analysis of glucose, fat, and protein metabolism in severely traumatized patients. Studies in the basal state and the response to total parenteral nutrition. Ann Surg 209, 63-72.

26. Lazzeri C, Sori A, Chiostri M, et al. (2009) Prognostic role of insulin resistance as assessed by homeostatic model assessment index in the acute phase of myocardial infarction in nondiabetic patients submitted to percutaneous coronary intervention. Eur J Anaesthesiol 26, 856-862.

27. Humberstone DA, Koea J \& Shaw JH (1989) Relative importance of amino acid infusion as a means of sparing protein in surgical patients. J Parenter Enteral Nutr 13, 223-227.

28. Charlton M \& Nair KS (1998) Protein metabolism in insulindependent diabetes mellitus. J Nutr 128, Suppl. 2, $323 \mathrm{~S}-327 \mathrm{~S}$.
29. Luzi L, Petrides AS \& De Fronzo RA (1993) Different sensitivity of glucose and amino acid metabolism to insulin in NIDDM. Diabetes 42, 1868-1877.

30. Gougeon R, Marliss EB, Jones PJ, et al. (1998) Effect of exogenous insulin on protein metabolism with differing nonprotein energy intakes in type 2 diabetes mellitus. Int $J$ Obes Relat Metab Disord 22, 250-261.

31. Charlton MR \& Nair KS (1998) Role of hyperglucagonemia in catabolism associated with type 1 diabetes: effects on leucine metabolism and the resting metabolic rate. Diabetes $\mathbf{4 7}$, 1748-1756.

32. Unger RH (1972) Insulin-glucagon ratio. Isr J Med Sci 8, 252-257.

33. Doglietto GB, Gallitelli L, Pacelli F, et al. (1996) Proteinsparing therapy after major abdominal surgery: lack of clinical effects. Protein-Sparing Therapy Study Group. Ann Surg 223, 357-362. 